\title{
(C) OPEN ACCESS \\ Identification of doctors at risk of recurrent complaints: a national study of healthcare complaints in Australia
}

\author{
Marie M Bismark, ${ }^{1}$ Matthew J Spittal, ${ }^{1}$ Lyle C Gurrin, ${ }^{1}$ Michael Ward, ${ }^{2}$ \\ David M Studdert ${ }^{1,3}$
}

- Additional material is published online only. To view please visit the journal online (http://dx.doi.org/10.1136/bmjqs2012-001691)

${ }^{1}$ Melbourne School of Population and Global Health, University of Melbourne, Parkville, Victoria, Australia

${ }^{2}$ School of Medicine, University of Queensland, Brisbane, Queensland, Australia

${ }^{3}$ Melbourne Law School, University of Melbourne, Parkville, Victoria, Australia

\section{Correspondence to}

Dr David M Studdert, Melbourne School of Population and Global Health, University of Melbourne, 207 Bouverie Street, Parkville,

VIC 3052, Australia,

d.studdert@unimelb.edu.au

Received 15 November 2012

Revised 23 January 2013 Accepted 24 January 2013

Published Online First

11 April 2013

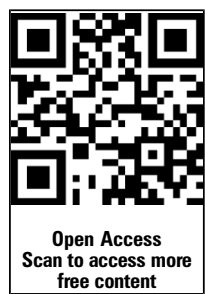

\section{SLinked}

- http://dx.doi.org/10.1136/ bmjas-2013-001880

- http://dx.doi.org/10.1136/ bmjas-2013-001902

- http://dx.doi.org/10.1136/ bmjqs-2013-002138

To cite: Bismark MM Spittal MJ, Gurrin LC, et al. BMJ Qual Saf 2013;22:

$532-540$

\begin{abstract}
Objectives (1) To determine the distribution of formal patient complaints across Australia's medical workforce and (2) to identify characteristics of doctors at high risk of incurring recurrent complaints.
\end{abstract}

Methods We assembled a national sample of all 18907 formal patient complaints filed against doctors with health service ombudsmen ('Commissions') in Australia over an 11-year period. We analysed the distribution of complaints among practicing doctors. We then used recurrent-event survival analysis to identify characteristics of doctors at high risk of recurrent complaints, and to estimate each individual doctor's risk of incurring future complaints. Results The distribution of complaints among doctors was highly skewed: $3 \%$ of Australia's medical workforce accounted for $49 \%$ of complaints and $1 \%$ accounted for a quarter of complaints. Short-term risks of recurrence varied significantly among doctors: there was a strong dose-response relationship with number of previous complaints and significant differences by doctor specialty and sex. At the practitioner level, risks varied widely, from doctors with $<10 \%$ risk of further complaints within 2 years to doctors with $>80 \%$ risk.

Conclusions A small group of doctors accounts for half of all patient complaints lodged with Australian Commissions. It is feasible to predict which doctors are at high risk of incurring more complaints in the near future. Widespread use of this approach to identify high-risk doctors and target quality improvement efforts coupled with effective interventions, could help reduce adverse events and patient dissatisfaction in health systems.

\section{INTRODUCTION}

To many doctors who are sued or complained against, the event seems random. At the population level, however, there are patterns. Previous studies have compared doctors who experienced multiple malpractice claims, ${ }^{1-5}$ complaints, ${ }^{6} 7$ and disciplinary actions ${ }^{8-10}$ with doctors who experienced few or none, and identified differences in the sex, age and specialty profile of the two groups. Such research helps to explain medico-legal risk retrospectively, but does not provide practical guidance for identifying risks prospectively. Clinical leaders, risk managers, liability insurers and regulators all lack reliable methods for systematically determining which doctors should be targeted for assistance and preventive action before they acquire troubling track records. Consequently, the medico-legal enterprise remains reactive, dealing primarily with the aftermath of adverse events and behaviours that lead to costly disputes.

The conventional wisdom is that future medico-legal events cannot be predicted at the doctor level with acceptable levels of accuracy. ${ }^{11} 12$ Numerous studies have tried, ${ }^{13-23}$ most with limited success. This body of research has two important shortcomings. First, only a few studies ${ }^{15} 1721$ report a method for predicting medicolegal risk that is potentially replicable, and these methods are statistically complex. The practical consequence is that regulators and liability insurers today have no clear way of estimating risk at the practitioner level, and doing so is not a standard part of risk management practice.

Second, no study to date has found a way to deal well with temporal aspects of risk, such as the evolving nature of doctors' medico-legal event histories, which can be crucial information in assembling a risk profile. Previous claims and complaints have been identified as an important predictor of future events, but only in analyses that specify this variable crudely-usually by 'freezing' a doctor's 
track record at a specific point to estimate a 'one-time' effect. ${ }^{13} 14 \quad 161719212425$ This approach is out of step with how claims and complaints are managed. The frontline challenges are to determine how a practitioner's risk profile changes over time as new information (including new events) comes to hand; when support or intervention measures to prevent further events are warranted; and how strong those measures should be. A risk prediction method that helped to address these questions would have considerable potential for boosting the contribution of medico-legal institutions to quality improvement.

We assembled a national sample of nearly 19000 formal healthcare complaints lodged against doctors in Australia between 2000 and 2011. We then used a time-to-event method of analysis to determine characteristics of doctors poised to incur recurrent complaints, and to estimate each practitioner's risk of recurrence at specific time points. The study had two main goals: to identify predictors of complaint-prone doctors in Australia, and to develop a robust and useful method for forecasting medico-legal risk.

\section{METHODS}

\section{Setting}

Health service commissions (Commissions) are statutory agencies established in each of Australia's six states and two territories. Commissions have responsibility for receiving and resolving patient complaints about the quality of healthcare services. Patients or their advocates must initiate complaints in writing, but the process is free and legal representation is optional. ${ }^{26}$

Table 1 compares the jurisdiction and functions of Commissions to those of the two other agencies that handle medico-legal matters in Australia-civil courts and the Medical Board of Australia.
Outside of the clinic or hospital in which care is received, Commissions are the primary avenue of redress for patients dissatisfied with the quality of care they have received. Plaintiffs' lawyers in Australia will rarely take on cases unless they have first proceeded through Commission processes (although the vast majority of complaints do not become negligence claims). At least 10 other Organisation for Economic Co-operation and Development (OECD) countries-including Austria, Finland, Israel, New Zealand and the UK-have similar bodies. ${ }^{27} 28$ In the UK, the closest analogue is the Parliamentary and Health Service Ombudsman.

Commissions in all Australian states and territories except South Australia participated in the study. These seven jurisdictions have 21 million residents and $90 \%$ of the nation's 88000 registered doctors. The study was approved by the ethics committee at the University of Melbourne.

\section{Data}

Between May 2011 and February 2012 we collected data on-site at Commission offices in each participating state and territory. Complaints against doctors were identified by querying the Commissions' administrative data systems. The filing period of interest spanned 12 years and differed slightly by jurisdiction: 2000-2011 for the Australian Capital Territory, the Northern Territory, Queensland, Tasmania and Victoria; 2000-2010 for Western Australia; and 2006-2011 for New South Wales.

All Commissions record the names of persons and institutions that are the subject of complaints, as well as the filing date, the nature of the complaint, the type of health professional named and their practice location. Although all Commissions recorded doctors' clinical specialty, the quality of this variable was mixed. Doctors' age and sex were not routinely

Table 1 Jurisdiction and functions of key agencies with responsibility for medico-legal matters in Australia

\begin{tabular}{|c|c|c|c|}
\hline & Civil courts & Health complaints commissions & Medical Board of Australia \\
\hline Cases handled & - Negligence claims & - Patient complaints & - Conduct, competence, or health matters \\
\hline $\begin{array}{l}\text { Jurisdictional } \\
\text { focus }\end{array}$ & $\begin{array}{l}\text { - Substandard care causing } \\
\text { patient harm }\end{array}$ & $\begin{array}{l}\text { - Low-quality care } \\
\text { - Patient dissatisfaction with care }\end{array}$ & $\begin{array}{l}\text { - Professional misconduct } \\
\text { - Performance or competence falling below } \\
\text { professional standards } \\
\text { - Ill-health, substance misuse, or impairment }\end{array}$ \\
\hline Procedures used & $\begin{array}{l}\text { Out-of-court negotiation } \\
\text { Alternative forms of dispute } \\
\text { resolution (eg, mediation, } \\
\text { arbitration) } \\
\text { - Trials before judges }\end{array}$ & $\begin{array}{l}\text { - Early resolution } \\
\text { - Conciliation } \\
\text { - Investigation }\end{array}$ & $\begin{array}{l}\text { - Review of doctor's competence or health } \\
\text { status } \\
\text { - Investigation } \\
\text { - Disciplinary charges }\end{array}$ \\
\hline Remedies & - Monetary damages & $\begin{array}{l}\text { Communication (eg, facilitate apology or } \\
\text { explanation) } \\
\text { - Restoration (eg, facilitate provision of further } \\
\text { treatment, fee forgiveness, monetary } \\
\text { settlement) } \\
\text { - Correction (eg, recommend system change) }\end{array}$ & $\begin{array}{l}\text { Correction (eg, requirement that practitioner } \\
\text { undergo education, rehabilitation, } \\
\text { monitoring etc) } \\
\text { Sanction (eg, suspension or revocation of } \\
\text { practice licence }{ }^{\star} \text { ) }\end{array}$ \\
\hline
\end{tabular}

\footnotetext{
*Typically, such sanctions are imposed by external administrative tribunals in proceedings initiated by the Medical Board of Australia.
} 
collected. We therefore supplemented the Commissions' administrative data with data from another source.

AMPCo Direct, a subsidiary of the Australian Medical Association, maintains a comprehensive list of doctors in Australia, including information on their sex, date of birth, specialty and subspeciality, and practice location. We purchased the AMPCo Direct database and matched doctors listed in it to doctors named in the complaints databases. The matching method is described in an online supplementary appendix.

\section{Variables}

We coded specialty into 13 categories, based on those promulgated by the Medical Board of Australia. ${ }^{29}$ Doctors' principal practice address was classified as urban or rural, based on the location of its postcode within a standard geographic classification system. ${ }^{30}$ The nature of concerns raised in complaints was sorted into 20 broad 'issue' categories. Commissions run dispute resolution processes; they generally do not rule on the merit of complaints, nor make findings for or against parties, so it was not possible to include a variable indicating how meritorious complaints were.

\section{Statistical analysis}

Distributional analysis

We plotted the cumulative distribution of complaints among two populations of doctors: (1) all unique doctors named in complaints and (2) all practicing doctors in the seven jurisdictions under study (ie, regardless of whether they had been named in complaints). The size of this second population was based on the number of doctors in employment in $2006,{ }^{31}$ the median study year. Because certain classes of complaints do not name doctors individually (eg. complaints arising in public hospitals in several of the study jurisdictions), we adjusted the proportions in the distributional calculations to ensure the numerators (number of complaints) matched the denominators (size of the 'exposed' segment of the medical workforce). Details are provided in the online supplementary appendix.

\section{Multivariable survival analysis}

We used multivariable survival analysis to identify predictors of doctors' risks of recurrent complaints. Specifically, we used an Anderson-Gill model ${ }^{32}$ in which the time-scale ran from time from first event (ie, a doctor's earliest complaint) and allowed each doctor in the sample to accrue multiple complaints over the period of observation. The outcome variable was the occurrence of a complaint against a doctor, conditional on the doctor having been named in an earlier complaint. The covariates were the number of prior complaints a doctor had experienced, jurisdiction, and the doctor's specialty, age, sex and principal practice location.

The number of prior complaints was specified as a time-varying covariate. Age was also time-varying in the sense that we allowed doctors to move into higher age categories, commensurate with their age at the time of the complaint. We fit cluster-adjusted robust SEs to account for doctors who experienced repeated complaints over time.

Details of model selection and specification are described in the online supplementary appendix. All statistical analyses were conducted using Stata 12.1.

\section{Risk predictions}

To estimate doctors' risks of experiencing complaints over time, we plotted adjusted failure curves. ${ }^{33}{ }^{34}$ Details of the statistical techniques used to create these curves are provided in the online supplementary appendix. We also plotted failure curves showing the predicted risk of recurrent complaints for several individual doctors. Values for all failure curves were computed using coefficients from the main multivariable model, and hence, derived from the survivor function, $S(\mathrm{t})$.

\section{Sensitivity analysis}

We tested the robustness of estimates from the main multivariable analysis by rerunning the analysis on a subsample of complaints $(n=10010)$ with issue codes suggestive of relatively serious concerns (namely, poor clinical care, breach of conditions, rough or painful treatment and sexual contact or relationship).

\section{RESULTS}

\section{Characteristics of complained-against doctors and complaints}

The study sample consisted of 18907 complaints against 11148 doctors. Sixty-one percent of the complaints addressed clinical aspects of care, most commonly concerns with treatment (41\%), diagnosis (16\%) and medications (8\%) (table 2). Nearly one quarter of complaints addressed communication issues, including concerns with the attitude or manner of doctors $(15 \%)$, and the quality or amount of information provided (6\%).

Seventy-nine percent of the doctors named in complaints were male, $47 \%$ were general practitioners and $14 \%$ were surgeons (table 3). Examples of several complaints are included in the online supplementary appendix.

\section{Incidence and distribution of complaints}

Doctors in the sample were complained against an average of 1.98 times (SD 2.31). The distribution was highly skewed, with a small subgroup of doctors accounting for a disproportionate share of complaints.

Figure 1 plots the cumulative distribution of complaints among doctors in six jurisdictions over a decade. (New South Wales data was not included in these plots because the complaints window there spanned only 5 years.) The curve on the left side of 
Table 2 Issues in a national sample of 18907 complaints filed by patients

\begin{tabular}{lcc}
\hline & $\mathrm{n}$ & $\%$ * \\
\hline Clinical care & 11579 & 61 \\
Treatment & 7746 & 41 \\
Diagnosis & 3080 & 16 \\
Medication & 1572 & 8 \\
Hygiene/infection control & 190 & 1 \\
Discharge/transfer & 113 & 0.6 \\
Other clinical care & 127 & 0.7 \\
Communication & 4279 & 23 \\
$\quad$ Attitude or manner & 2823 & 15 \\
Information & 1132 & 6 \\
Consent & 582 & 3 \\
Other communication & 32 & 0.2 \\
Costs or billing & 1309 & 7 \\
Medical records, certificates, or reports & 1304 & 7 \\
Access and timeliness & 1257 & 7 \\
Sexual contact or relationship & 625 & 3 \\
Rough or painful treatment & 477 & 3 \\
Confidentiality or information privacy & 392 & 2 \\
Breach of conditions & 332 & 2 \\
Grievance handling & 213 & 1 \\
Discrimination & 103 & 0.5 \\
Other & 126 & 0.7 \\
\hline Complant issues sum to mor than & $50 \%$ can &
\end{tabular}

${ }^{*}$ Complaint issues sum to more than $100 \%$ because some complaints involved multiple issues.

the figure shows the distribution of complaints among doctors who experienced one or more complaints in the decade. Fifteen percent of doctors named in complaints accounted for $49 \%$ of all complaints, and 4\% accounted for a quarter of all complaints. The curve on the right side of the figure shows the distribution of complaints across the full population of practicing doctors, not just those who experienced complaints. Three percent of all doctors accounted for $49 \%$ of all complaints, and $1 \%$ accounted for a quarter of all complaints.

\section{Multivariable predictors of recurrent complaints}

In multivariable analyses, the number of prior complaints doctors had experienced was a strong predictor of subsequent complaints, and a dose-response relationship was evident (table 4). Compared with doctors with one prior complaint, doctors with two complaints had nearly double the risk of recurrence (HR 1.93; 95\% CI 1.79 to 2.09), and doctors with five prior complaints had six times the risk of recurrence (HR 6.16; 95\% CI 5.09 to 7.46). Doctors with 10 or more prior complaints had 30 times the risk of recurrence (HR 29.56; 95\% CI 19.24 to 45.41$)$.

Risk of recurrence also varied significantly by specialty. Compared with general practitioners, plastic
Table 3 Characteristics of 11148 doctors named in complaints

\begin{tabular}{|c|c|c|}
\hline & $\mathbf{n}$ & $\%$ \\
\hline \multicolumn{3}{|l|}{ Gender } \\
\hline Male & 8818 & 79 \\
\hline Female & 2255 & 20 \\
\hline Missing & 75 & 1 \\
\hline \multicolumn{3}{|l|}{ Speciality } \\
\hline General practice & 5289 & 47 \\
\hline Surgery & 1540 & 14 \\
\hline Orthopaedic & 432 & 4 \\
\hline General & 398 & 4 \\
\hline Plastic & 177 & 2 \\
\hline Other surgical & 533 & 5 \\
\hline Internal medicine & 1243 & 11 \\
\hline Obstetrics and gynaecology & 541 & 5 \\
\hline Psychiatry & 672 & 6 \\
\hline Anaesthesia & 404 & 4 \\
\hline Ophthalmology & 243 & 2 \\
\hline Dermatology & 157 & 1 \\
\hline Radiology & 200 & 2 \\
\hline Other & 501 & 4 \\
\hline Missing & 358 & 3 \\
\hline \multicolumn{3}{|l|}{ Age } \\
\hline 22-35 years & 757 & 7 \\
\hline $36-45$ years & 2624 & 24 \\
\hline $46-55$ years & 3354 & 30 \\
\hline $56-65$ years & 2184 & 20 \\
\hline $66+$ years & 691 & 6 \\
\hline Missing & 1583 & 14 \\
\hline \multicolumn{3}{|l|}{ Practice location } \\
\hline Urban & 8241 & 74 \\
\hline Rural & 2775 & 25 \\
\hline Missing & 132 & 1 \\
\hline
\end{tabular}

surgeons had twice the risk (HR 2.04; 95\% CI 1.75 to 2.38), and risks were approximately 50\% higher among dermatologists (HR 1.56; 95\% CI 1.30 to 1.88 ) and obstetrician-gynecologists (HR 1.50; 95\% CI 1.29 to 1.76). Anaesthetists had significantly lower risks of recurrence (HR 0.65; 95\% CI 0.54 to 0.79).

Male doctors had a $40 \%$ higher risk of recurrence than their female colleagues (HR 1.36; 95\% CI 1.23 to 1.50 ). Location of practice (urban vs rural) was not significantly associated with recurrence. Compared with doctors 35 years of age or younger, older doctors had $30-40 \%$ higher risks of recurrence; this level of heightened risk was similar through the middle-aged and older-aged groups.

\section{Risks of recurrence over time}

Doctors named in a third complaint had a 38\% chance of being the subject of a further complaint within a year, and a $57 \%$ probability of being complained against again within 2 years (figure $2 \mathrm{~A}$ ). Doctors named in a fifth complaint had a 59\% 1-year 


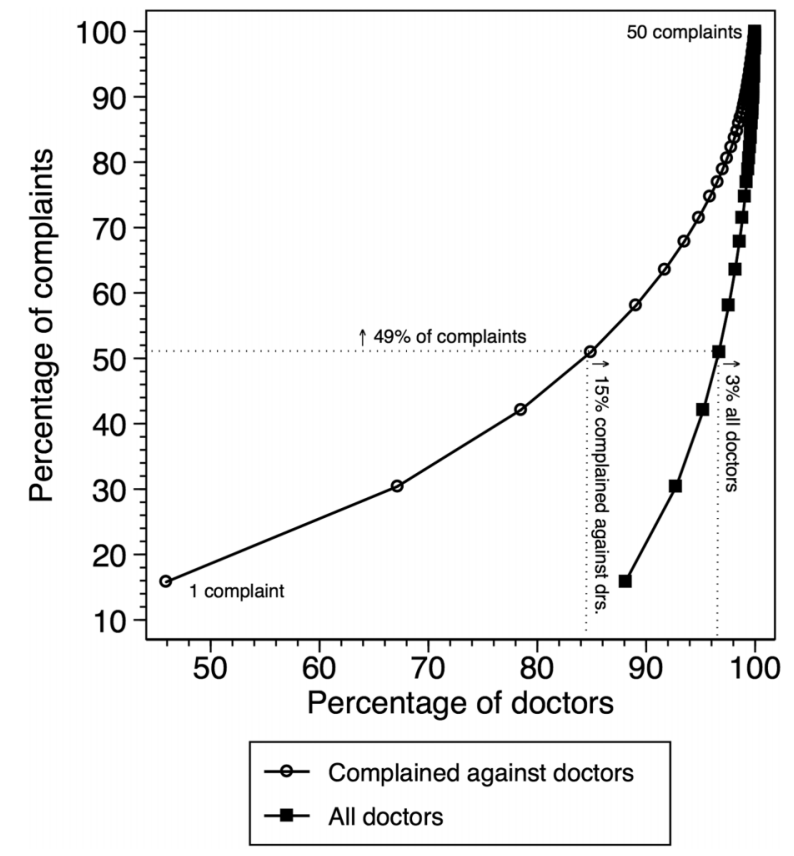

Figure 1 Cumulative distribution of complaints and doctors named in complaints.

complaint probability and a 79\% 2-year complaint probability. Recurrence was virtually certain for doctors who had experienced 10 or more complaints, with 97\% incurring another complaint within a year. Regardless of the number of previous complaints, doctors' risks of further complaints increased sharply in the first 6 months following a complaint, and then declined steadily thereafter. This is evident from the steep rise and then plateauing of the curves in figure $2 \mathrm{~A}$ (these curves plot cumulative risks over time).

The curves shown in figure $2 \mathrm{~A}$ depict average population-level risks for selected predictors, controlling for other covariates. However, our modelling approach is fundamentally designed to predict risk at the practitioner level. Figure 2B illustrates this; it shows wide variation in risk profiles among a selection of seven doctors in the sample. Doctor A, for instance, is a 62-year-old male general practitioner who accumulated 10 complaints over 9.2 years of observation. He had a $39 \%$ risk of recurrence after his fourth complaint, a $61 \%$ risk after his fifth complaint and a 94\% risk after his sixth complaint.

\section{Sensitivity analysis}

Re-estimating the main multivariable model using a subset of 'severe' complaints produced very similar results to the main model. The online supplementary appendix shows the full set of results.

\section{DISCUSSION}

This study of patient complaints made to the chief health-quality regulators in Australia found that the complaints clustered heavily among a small group of
Table 4 Multivariable regression analysis estimating risk of recurrent complaints*

\begin{tabular}{|c|c|c|}
\hline & HR $(95 \% \mathrm{Cl})$ & $\mathrm{p}$ Value \\
\hline Number of prior complaints & & $<0.001$ \\
\hline 1 (ref) & 1.00 & \\
\hline 2 & 1.93 (1.79 to 2.09$)$ & \\
\hline 3 & 3.21 (2.87 to 3.59 ) & \\
\hline 4 & 4.54 (3.90 to 5.27$)$ & \\
\hline 5 & 6.16 (5.09 to 7.46$)$ & \\
\hline 6 & 8.83 (7.05 to 11.05$)$ & \\
\hline 7 & 9.57 (7.40 to 12.37$)$ & \\
\hline 8 & 9.49 (7.05 to 12.77$)$ & \\
\hline 9 & 16.09 (11.72 to 22.10$)$ & \\
\hline 10 or more & 29.56 (19.24 to 45.41$)$ & \\
\hline States and territories & & $<0.001$ \\
\hline 1 (ref) & 1.00 & \\
\hline 2 & 2.23 (1.86 to 2.67$)$ & \\
\hline 3 & 2.10 (1.75 to 2.53$)$ & \\
\hline 4 & 1.91 (1.53 to 2.37$)$ & \\
\hline 5 & 1.86 (1.52 to 2.29$)$ & \\
\hline 6 & 1.73 (1.37 to 2.20$)$ & \\
\hline 7 & 1.25 (1.02 to 1.53$)$ & \\
\hline Male doctor & $1.36(1.23$ to 1.50$)$ & $<0.001$ \\
\hline Urban practice location & 0.98 (0.90 to 1.07$)$ & 0.65 \\
\hline Specialty of doctor & & $<0.001$ \\
\hline Plastic surgery & 2.04 (1.75 to 2.38$)$ & \\
\hline Dermatology & 1.56 (1.30 to 1.88$)$ & \\
\hline Obstetrics and gynaecology & 1.50 (1.29 to 1.76$)$ & \\
\hline General surgery & $1.45(1.17$ to 1.80$)$ & \\
\hline Orthopaedic surgery & $1.32(1.20$ to 1.44$)$ & \\
\hline Other surgery & $1.30(1.19$ to 1.43$)$ & \\
\hline Ophthalmology & 1.19 (1.02 to 1.40$)$ & \\
\hline Psychiatry & 1.15 (1.02 to 1.29$)$ & \\
\hline General practice (ref) & 1.00 (ref.) & \\
\hline Internal medicine & 0.93 (0.80 to 1.09$)$ & \\
\hline Radiology & 0.89 (0.34 to 2.37$)$ & \\
\hline Anaesthesia & 0.65 (0.54 to 0.79$)$ & \\
\hline Other & 0.65 (0.51 to 0.82$)$ & \\
\hline Age of doctor & & $<0.001$ \\
\hline$<35$ years & 1.00 (ref.) & \\
\hline $36-45$ years & $1.31(1.13$ to 1.51$)$ & \\
\hline $46-55$ years & $1.40(1.22$ to 1.62$)$ & \\
\hline $56-65$ years & 1.43 (1.23 to 1.67$)$ & \\
\hline Gamma & $-0.21(-0.23$ to -0.19$)$ & \\
\hline
\end{tabular}

${ }^{*}$ Analysis based on 14986 index complaints against 8749 doctors, and 6237 subsequent complaints.

doctors. Approximately $3 \%$ of practicing doctors accounted for half of all complaints. The number of prior complaints doctors had experienced was a particularly strong predictor of their short-term risk of further complaints. At the practitioner level, shortterm risks of recurrence varied widely, from $<10 \%$ risk among low-risk doctors to $>80 \%$ risk among high-risk doctors. Overall, recurrent-event survival 
(A) By number of previous complaints doctors had experienced*

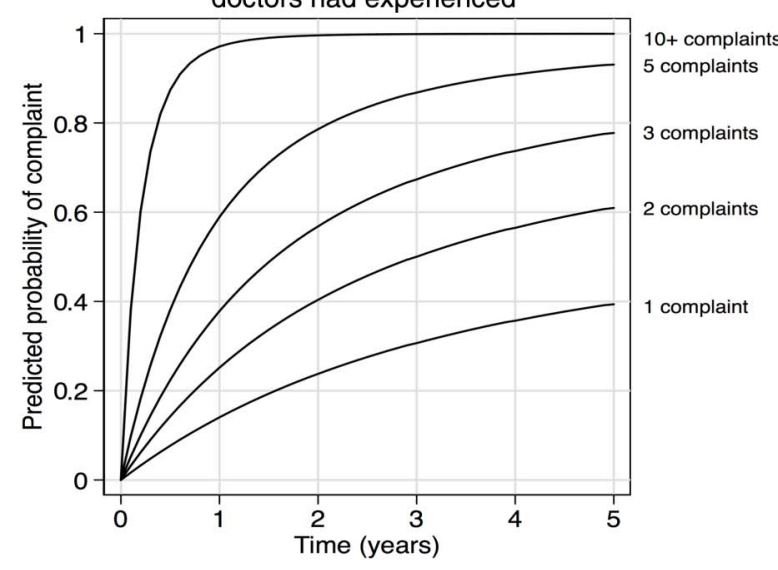

(B) By selected doctors ${ }^{\dagger \neq}$

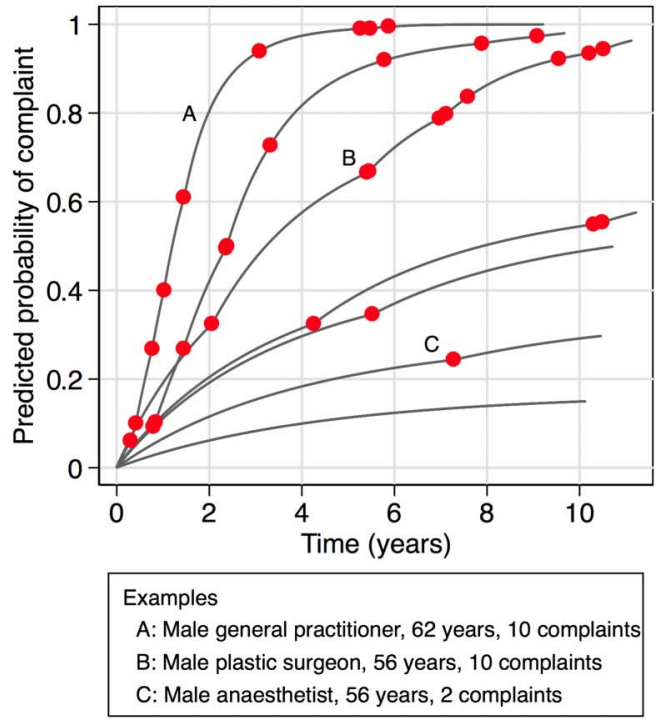

Figure 2 Probability of recurrent complaints over time.

${ }^{*}$ Curves adjusted for doctor age and sex, practice location, specialty, state and complaint year. ${ }^{\dagger}$ Dots on the curves indicate points in time when actual complaints occurred (ie, $x$-axis), but have no meaning in relation to predicted probability of complaints (ie, $y$-axis).

${ }^{\ddagger}$ Ages reported refer to mid-points of the period over which the doctor was followed.

analysis showed considerable promise as a statistical approach for flagging complaint-prone doctors early in their complaints trajectory, using only a few simple descriptive characteristics.

Our study used a national sample to examine the distribution and predictors of medico-legal events. Patients treated in healthcare facilities throughout seven states and territories were eligible to file complaints with a Commission about the quality of the care they received. Previous studies of claims and complaints risk have tended to focus on pools of doctors covered by a single liability insurer or a few hospitals.

The extent to which complaints were concentrated in a small group of doctors was striking, consistent with other studies of complaints ${ }^{7} 1922$ and claims. ${ }^{18}$ This highly skewed distribution of medico-legal events among doctors has several implications. The obvious one is that there is a pressing need for interventions that address the behaviour of doctors who are chronically complained or claimed against. Medical boards in Australia and elsewhere already address conduct, competence and health concerns with certain practitioners, but these efforts may fall short. Our study identifies a target population within which systematic deployment of interventions to improve performance $^{3536}$ might be manageable: less than 500 doctors accounted for $25 \%$ of all complaints that named doctors in the decade under study. Immediate steps to improve, guide or constrain the care being provided by these 'high-risk' practitioners could be a very costeffective way to advance quality and safety, and produce measurable benefits at the system level.

A more sobering implication of the clustering phenomenon is that remediation activities targeted at doctors who have attracted many complaints, while critical, come too late. Complaints are best understood as sentinel events, and complainants as representatives of much larger groups of harmed or dissatisfied patients. ${ }^{37-39}$ By the time multiple complaints have accrued, substantial damage to quality of care is likely to have occurred already. The clustering of medicolegal events highlights the huge gains that would be put in reach by a capability to identify early doctors who are on course to incur multiple complaints.

Our approach is ripe for replication, not only by hospitals and regulators that hold complaints data, but within liability insurers with malpractice claims data, large hospital systems with risk management data, and medical boards and other professional bodies with data on disciplinary matters. Several distinctive aspects of our approach, descriptions of which follow, pave the way for better prediction of medico-legal risk in these settings than has been achieved to date.

Previous efforts to predict malpractice risk in liability insurance pools have included doctors with and without claims in their analyses. ${ }^{11} 14 \quad 15171921$ This approach suits a core goal in many of these studies: to explore the feasibility of 'experience rating' doctors' liability insurance premiums. ${ }^{24} 40$ By contrast, our study sought to predict risk for purposes of targeting quality-improvement interventions. In this context, it is appropriate to focus on doctors who have been the subject of at least one complaint because this is the group with whom regulators have a natural point of contact and opportunities to intervene. An ancillary benefit of this 'conditional' approach to modelling medico-legal risk is that it enhances the ability to identify strong predictors of recurrent risk. 
A key technical challenge encountered in previous studies has been how to deal with the recurrent nature of medico-legal events. The approach used by Rolph $^{11} 14 \quad 21$ and others who have emulated his method, ${ }^{15} 1724$ 'fixes' the effect of prior events in a single variable at the doctor level. The 'weighted sum algorithm' behind the PARS risk score, developed by Hickson and colleagues, comes from analyses regressing a sample of 'risk management events' on information obtained from unsolicited patient complaints. ${ }^{19} 25$ A limitation of both approaches is their static consideration of doctors' event histories. In its application, however, the PARS algorithm adopts dynamic features (doctors risk scores can be recalculated as new complaints appear over time).

An advantage of recurrent-event survival analysis is that it permits dynamic consideration of the effect of time-varying factors in the predictive model itself. In other words, it is not necessary to rely on a snapshot taken of a doctor's situation at a particular point in time: as risk profiles evolve-and the coefficients on the previous complaints variable in our study illustrate how dramatically this may occur-survival analysis incorporates these changes into the estimation of future risk. A related advantage of survival analysis is that it permits estimation of doctors' risk levels at different points in time-a year after an index event, 2 years later and so on. Our analysis showed that for some predictors, particularly the number of previous complaints, doctors' risks of additional complaints were non-linear: the risk tends to rise quickly over the several months after a complaint and then level off by the time the doctor reaches a year without further incidents. For clinical leaders, regulators and liability insurers trying to determine when in a doctor's trajectory of events to intervene to prevent recurrence, and how aggressively, this kind of temporal information may be very informative.

Our study has several limitations. First, the generalisability of our findings and method-to other types of medico-legal events, to other types of health practitioners, and outside Australia-is unknown, and should be tested. In other medico-legal settings, it may not be possible for practitioners to accrue the large numbers of events that some doctors in our sample did. Lower ceilings on the number of prior events may reduce the predictive value of this variable. Nonetheless, our analyses showed high risks of recurrence within 2 years (>60\%) among doctors with as few as four complaints.

Second, the predictors we examined were doctorfocused. Other variables-including, patient characteristics, ${ }^{41-44}$ case-type and outcomes, ${ }^{39} 45$ doctors' ethnicity and country of training, ${ }^{46} 47$ the practice setting, and aspects of the patient-doctor relationship ${ }^{48}$-may also predict complaint risk. However, because these variables are usually more difficult to measure at the population level, their suitability for large-scale predictive modelling is questionable. Moreover, given the high predictive values obtained with the simple doctor-level variables used in our analysis, the scope to boost predictive values with the addition of other variables is limited. Finally, we used head counts of practitioners, not more sophisticated measures of doctors' exposure to complaint risk, such as volume of patients treated or procedures conducted.

During the rise of the quality and safety movement over the last 15 years, medico-legal institutions have been largely on the sidelines. They remain essentially reactive enterprises, with workloads that focus on dealing with the fallout from care that has gone wrong. Patient safety experts regard the medico-legal system's fixation with posthoc assessments of individual behaviour, rather than prevention and systems, as anachronistic. ${ }^{49}$ But as Rolph recognised 30 years ago, ${ }^{11}$ methods for accurately and reliably forecasting the medico-legal risk of clinicians have transformative potential because they could focus and drive prevention. Identifying and intervening early with doctors at high risk of attracting recurrent medico-legal events has considerable potential to reduce adverse events and patient dissatisfaction system-wide; it may also help those doctors avoid the vicissitudes of medico-legal processes.

Acknowledgements We thank the health services commissioners and their staff in the Australian Capital Territory, New South Wales, the Northern Territory, Queensland, South Australia, Tasmania, Victoria and Western Australia; their support, assistance and advice made this study possible. Troyen Brennan, Atul Gawande, Michelle Mello and John Rolph provided helpful comments on earlier drafts of this manuscript.

Contributors MB, MS and DS developed the study idea, collected the data and conducted the analyses; $\mathrm{MB}$ and DS wrote the first draft of the manuscript; MW advised on design of the study, contributed expertise in interpretation and analysis of study data, and helped revise the draft manuscript; LG contributed to design and conduct of the statistical analysis and helped revise the draft manuscript; all authors reviewed and agreed on the submitted version of the manuscript. MB, MS and DS are guarantors for the study.

Funding This study was funded by an ARC Laureate Fellowship (FL110100102 to Dr Studdert) from the Australian Research Council. The research was conducted independently from the funder. The funder had no role in the study design, collection, analysis, and interpretation of data; writing of the report, or the decision to submit the article for publication.

Competing interests All authors have completed the Unified Competing Interest form and declare that: (1) MB, MS and DS have support from the Australian Research Council (Laureate Fellowship to DS); (2) none of the authors have had a financial relationships with any organisation that may have an interest in the submitted work in the previous 3 years; (3) none of the authors' spouses, partners or children have any financial relationships that may be relevant to the submitted work and (4) none of the authors have any non-financial interests that may be relevant to the submitted work.

Ethics approval The study was approved by the Human Research Ethics Committee at the University of Melbourne

Provenance and peer review Not commissioned; externally peer reviewed.

Open Access This is an Open Access article distributed in accordance with the Creative Commons Attribution Non Commercial (CC BY-NC 3.0) license, which permits others to distribute, remix, adapt, build upon this work non-commercially, 
and license their derivative works on different terms, provided the original work is properly cited and the use is non-commercial. See: http://creativecommons.org/licenses/by-nc/3.0/

\section{REFERENCES}

1 Sloan FA, Mergenhagen PM, Burfield WB, et al. Medical malpractice experience of physicians. Predictable or haphazard? JAMA 1989;262:3291-7.

2 Taragin MI, Wilczek AP, Karns ME, et al. Physician demographics and the risk of medical malpractice. Am J Med 1992;93:537-42.

3 Adamson TE, Baldwin DC Jr, Sheehan TJ, et al. Characteristics of surgeons with high and low malpractice claims rates. West $J$ Med 1997;166:37-44.

4 Abbott RL, Ou RJ, Bird M. Medical malpractice predictors and risk factors for ophthalmologists performing LASIK and photorefractive keratectomy surgery. Ophthalmology 2003;110:2137-46.

5 Jena AB, Seabury S, Lakdawalla D, et al. Malpractice risk according to physician specialty. N Engl J Med 2011;365:629-36.

6 Nash LM, Kelly PJ, Daly MG, et al. Australian doctors' involvement in medicolegal matters: a cross-sectional self-report study. Med J Aust 2009;191:436-40.

7 Bismark MM, Spittal MJ, Studdert DM. Prevalence and characteristics of complaint-prone doctors in private practice in Victoria. Med J Aust 2011;195:25-8.

8 Morrison J, Wickersham P. Physicians disciplined by a state medical board. JAMA 1998;279:1889-93.

9 Kohatsu ND, Gould D, Ross LK, et al. Characteristics associated with physician discipline: a case-control study. Arch Intern Med 2004;164:653-8.

10 Papadakis MA, Teherani A, Banach MA, et al. Disciplinary action by medical boards and prior behavior in medical school. N Engl J Med 2005;353:2673-82.

11 Rolph JE. Some statistical evidence on merit rating in medical malpractice insurance. J Risk Insur 1981;48(2):247-60.

12 Danzon PM. Liability for medical malpractice. J Econ Perspect 1991;5:51-69.

13 Venezian EC, Nye BF, Hofflander AE. The distribution of claims for professional malpractice: some statistical and public policy aspects. J Risk Insur 1989;56:686-701.

14 Rolph JE, Kravitz RL, McGuigan K. Malpractice claims data as a quality improvement tool. II. Is targeting effective? JAMA 1991;266:2093-7.

15 Cooil B. Using medical malpractice data to predict the frequency of claims. J Am Stat Assoc 1991;85:285-95.

16 Bovbjerg RR, Petronis R. The relationship between physicians' malpractice claims history and later claims: Does the past predict the future? JAMA 1994;272:1421-6.

17 Gibbons RD, Hedeker D, Charles SC, et al. A random-effects probit model for predicting medical malpractice claims. J Am Stat Assoc 1994;89:760-67.

18 Weycker DA, Jensen GA. Medical malpractice physicians: Who will be sued and who will pay? Health Care Manag Sci 2000;3:269-77.

19 Hickson GB, Federspeil CF, Pichert JW, et al. Patient complaints and malpractice risk. JAMA 2002;287:2951-7.

20 Khaliq AA, Dimassi H, Huang CY, et al. Disciplinary action against physicians: who is likely to get disciplined? Am J Med 2005;118:773-7.

21 Rolph JE, Adams JL, McGuigan KA. Identifying malpracticeprone physicians. J Empirical Legal Stud 2007;4:125-53.
22 Hickson GB, Federspiel CF, Blackford J, et al. Patient complaints and malpractice risk in a regional healthcare center. South Med J 2007;100:791-6.

23 Tamblyn R, Abrahamowicz M, Dauphinee D, et al. Physician scores on a national clinical skills examination as predictors of complaints to medical regulatory authorities. JAMA 2007;298:993-1001.

24 Nye BF, Hofflander AE. Experience rating in medical professional liability insurance. J Risk Insur 1988;55:150-7.

25 Moore IN, Pichert JW, Hickson GB, et al. Rethinking peer review: detecting and addressing medical malpractice claims risk. Vanderbilt Law Rev 2006;59:1175-206.

26 Bismark MM, Spittal MJ, Gogos AJ, et al. Remedies sought and obtained in healthcare complaints. BMJ Qual Saf 2011; 20:806-10.

27 Fallberg L, MacKenney S. Patient ombudsmen in seven European countries: an effective way to implement patients' rights? Eur J Health Law 2003;10:343-57.

28 Paterson R. The patients' complaints system in New Zealand. Health Aff (Millwood) 2002;21:70-9.

29 Medical Board of Australia. List of specialties, fields of specialty practice, and related specialist titles. http://www.medicalboard.gov. $\mathrm{au} /$ Registration/Types/Specialist-Registration/Medical-Specialtiesand-Specialty-Fields.aspx (accessed Feb 2011).

30 Australian Bureau of Statistics. Australian Standard Geographical Classification System (ASCG). ABS cat no. 1216.0, Canberra: ABS, 2005.

31 Australian Institute of Health and Welfare. Medical labour force 2006. Cat. no. HWL 42. Canberra: AIHW, 2008.

32 Cook RJ, Lawless JF. The statistical analysis of recurrent events. New York: Springer-Verlag, 2007.

33 Makuch RW. Adjusted survival curve estimation using covariates. J Chronic Dis 1982;35:437-43.

34 Nieto FJ, Coresh J. Adjusting survival curves for confounders: a review and a new method. Am J Epidemiol 1996; 143:1059-68.

35 National Clinical Assessment Service. NCAS casework: the first eight years. London: NHS, 2009.

36 Hickson GB, Pichert JW, Webb LE, et al. A complementary approach to promoting professionalism: identifying, measuring, and addressing unprofessional behaviors. Acad Med 2007;82:1040-8.

37 Murff HJ, France DJ, Blackford J, et al. Relationship between patient complaints and surgical complications. Qual Saf Health Care 2006;15:13-16.

38 Sage WM. Putting the patient in patient safety: linking patient complaints and malpractice risk. JAMA 2002;287:3003-5.

39 Bismark MM, Brennan TA, Paterson RJ, et al. Relationship between complaints and quality of care in New Zealand: a descriptive analysis of complainants and non-complainants following adverse events. Qual Saf Health Care 2006; 15:17-22.

40 Ellis RP, Gallup CL, McGuire TG. Should medical professional liability insurance be experience rated? J Risk Insur 1991; 57:66-78.

41 Lester R, Wilson B, Griffin L, et al. Unusually persistent complainants. Brit J Psych 2004;184:352-6.

42 Carroll KN, Cooper WO, Blackford JU, et al. Characteristics of families that complain following pediatric emergency visits. Ambul Pediatr 2005;5:326-31.

43 Fishbain DA, Brus D, Disorbio JM, et al. What patient attributes are associated with thoughts of suing a physician. Arch Phys Med Rehabil 2007;88:589-96. 
44 Wu CY, Lai HJ, Chen RC. Patient characteristics predict occurrence and outcome of complaints against physicians: a study from a medical center in central Taiwan. J Formos Medical Assoc 2009;108:126-34.

45 Vincent C, Phillips A, Young M. Why do people sue doctors? A study of patients and relatives taking legal action. Lancet 1994;343:1609-13.

46 Humphrey C, Hickman S, Gulliford MC. Place of medical qualification and outcomes of UK General Medical Council 'fitness to practise' process: cohort study. BMJ 2011; 342:d1817.
47 Elkin K, Spittal MJ, Studdert DM. Risks of complaints and adverse disciplinary findings against international medical graduates in Victoria and Western Australia. Med J Aust 2012;197:448-52.

48 Levinson W, Roter DL, Mullooly JP, et al. Physician-patient communication: the relationship with malpractice claims among primary care physicians and surgeons. JAMA 1997;277:553-9.

49 Studdert DM, Brennan TA. No-fault compensation for medical injuries: the prospect for error prevention. JAMA 2001;286:217-23. 